\title{
OCUPAR, PRODUZIR E RESISTIR: UM BREVE ESTUDO SOBRE A PROPOSTA PEDAGÓGICA DO MOVIMENTO DOS TRABALHADORES RURAIS SEM TERRA (MST) EM COMPARAÇÃO COM A BASE NACIONAL COMUM CURRICULAR (BNCC)
}

\author{
OCCUPY, PRODUCE AND RESIST: A BRIEF STUDY ON THE \\ PEDAGOGICAL PROPOSAL OF THE LANDLESS RURAL \\ WORKERS MOVEMENT (MST) IN COMPARISON WITH THE \\ NATIONAL COMMON CURRICULAR BASE (BNCC)
}

Jean Marcel Caum Camoleze ${ }^{1}$

\begin{abstract}
RESUMO
A finalidade deste artigo é apresentar a proposta pedagógica em assentamentos e acampamentos do Movimento dos Trabalhadores Rurais Sem Terra (MST) em comparação com a Base Nacional Comum Curricular (BNCC) na modalidade de Educação do Campo. Além de utilizarmos as diretrizes e considerarmos as dificuldades da Educação do Campo, também destacaremos as particularidades de uma proposta pedagógica voltada à formação de educadores e educandos do Movimento. Surgido no início de 1984, o MST tornou-se o principal movimento social do país, seja em âmbito urbano ou rural, sendo o setor responsável pela educação considerado como prioritário. Com o objetivo principal de garantir o direito à terra, o MST reconhece que a educação do campesinato é essencial para a continuidade de sua luta. Observando a trajetória histórica e a formação dos educadores que atuam em acampamentos e assentamentos, apontaremos as necessidades e singularidades da Educação do Campo em um movimento rural que se encontra às margens do sistema institucionalizado. Com isso, pretendemos demonstrar que a educação no MST transpassa a disputa entre Movimento e Estado, colocando-se em situação de primazia para a formação integral dos sujeitos e a superação do ensino restrito a competências.
\end{abstract}

Palavras-Chave: MST. Educação do Campo. BNCC. Educação Integral.

\footnotetext{
ABSTRACT

This article aims to demonstrate the pedagogical proposal in settlements and camps of the Landless Rural Workers Movement (MST) in relation to the National Common Curriculum Bases (BNCC). In addition to using the guidelines and difficulties of rural education, it also has its particularities thought of in a pedagogical proposal, which need to be overcome in the education of educators and students of the Movement. Founded in early 1984, the MST became the main social movement in the country, whether in urban or rural areas, and the sector responsible for education was one of the first to become priority three. With the main objective of guaranteeing the struggle for the right to land, the MST recognizes that the education of the peasantry is also essential for the continuity of its struggle. Observing the historical trajectory and the training of educators who work in camps and settlements, we will point out the needs and singularities of rural education focused on a rural movement that are on the margins of an institutionalized system. With this, we intend to show that the education of the MST goes beyond the dispute between the

1 Mestre e doutorando em Ciência da Informação pela UNESP/Campus Marília, Professor da Rede Pública de Educação do Municipal de Cajamar, E-mail: jean.camoleze@unesp.br, ORCID https://orcid.org/0000-0003-2182-1740 e Lattes http://lattes.cnpq.br/2523337203830340.
} 
Movement and the State, placing education as a primacy in integral education and overcoming the restricted competences.

Keywords: MST. Rural Education. BNCC. Integral Education.

\section{INTRODUÇÃO}

O título atribuído ao artigo remete ao estabelecido no $5^{\circ}$ Encontro do MST, realizado no ano de 1989, em Sumaré-SP, e no $2^{\circ}$ Encontro Nacional do MST, que ocorreu em maio de 1990, na capital federal, quando se consolidaram as palavras de ordem que permanecem até os dias atuais: ocupar, resistir e produzir. Ainda que os termos façam referência à reforma agrária, também poderiam ser utilizados pelos educandos do Movimento, pois, neste período, se iniciava a luta pelos direitos básicos dos primeiros assentados e acampados, sendo a educação um dos principais focos.

A luta pela terra trouxe ao Movimento uma ampliação em suas frentes ao integrar outros direitos às pautas de reuniões, congressos e encontros. Em 1987, foi criado o Setor Nacional de Educação que tinha como proposta dois eixos principais: a reivindicação pelo direito à educação e a construção de uma nova pedagogia, formulação que resultaria na “Proposta de Educação do MST” (CALDART, 1997)

Trinta anos depois foi aprovada e homologada a Base Nacional Comum Curricular (BNCC) que tem por intuito nortear o trabalho das escolas e dos professores em todos os anos e componentes curriculares. Entretanto, o termo Educação do Campo é citado uma única vez apenas (BRASIL, 2017), desconsiderando, assim, as especificidades pedagógicas do meio rural.

Nesta perspectiva, cabe a reflexão sobre a proposta do MST, tendo como referência a BNCC. Afinal, qual a relevância de uma proposta pedagógica para contemplar a Educação do Campo? Entre a proposta do MST e a da BNCC qual é a que mais considera a realidade do trabalhador e educando do meio rural? Por fim, qual a diferença entre a proposta institucional da BNCC para a Educação do Campo e os ideais pedagógicos do MST?

Diante disso, temos como objetivo produzir um breve estudo comparativo entre a construção da modalidade de Educação do Campo realizada por um movimento socialmente formado por trabalhadores rurais, o MST, e aquela desenvolvida pelo Ministério da Educação (MEC) dentro da Base Nacional Comum Curricular (BNCC), homologada em 20 de dezembro de 2017.

Surgem, assim, concepções diferentes para a prática de educadores e educandos no campo. Priorizamos analisar a "Proposta de Educação do MST" e seus objetivos em oposição aos métodos pedagógicos utilizados principalmente na Educação do Campo. A ideia não é proceder a um comparativo quantitativo entre os modelos educacionais, mas a compreensão 
entre a visão do Movimento sobre a educação e o quanto esta foi ou não contemplada na Base Nacional Comum Curricular (BNCC) do Ministério da Educação (MEC).

Buscaremos altercar o campo teórico metodológico da educação como uma práxis social do Movimento, que não está embasada somente na educação formal, mas também na educação não formal e na construção social existente dentro do coletivo.

Ressaltamos que a Educação do Campo é uma modalidade de ensino que objetiva ser “[...] planejada e estruturada a partir das necessidades educacionais de cada região" (THERRIEN e DAMASCENO, 1993, p. 30). Apresentá-la é também discutir perspectivas e dimensões que a reconhecem no meio rural, considerando as suas especificidades e, sobretudo, as reais condições de estudos de seu trabalhador e seus descendentes.

Nesse sentido, defendemos a Educação do Campo focada no sujeito e em sua realidade, o que:

[...] implica buscar apreender as contradições e tensões que estão na realidade que a produziu e que a move, e que ela ajuda a produzir e mover; que estão no "estado da coisa", afinal, e não apenas nas ideias ou entre ideias sobre o que dela se diz. (CALDART, 2009, p. 38).

A modalidade de Educação do Campo é um conceito dicotômico da Educação Rural, cujos interesses estavam voltados apenas para estabelecer e dar continuidade às divergências sociais entre uma elite agrária e uma massa de trabalhadores rurais com restrições ao conhecimento. Neste ponto, destacamos sua definição como uma “[...] política educacional voltada para o desenvolvimento do território camponês como parte do campo brasileiro. Este território é um campo específico e diverso que possui singularidade na sua organização por meio do trabalho familiar." (FERNANDES, 2006, p. 29).

A modalidade de Educação do Campo apresenta, portanto, a proposta de ressaltar o educando como sujeito crítico e autônomo, como destaca Caldart (2009, p. 39):

A Educação do Campo nasceu como crítica à realidade da educação brasileira, particularmente à situação educacional do povo brasileiro que trabalha e vive no/do campo. Esta crítica nunca foi à educação em si mesma porque seu objeto é a realidade dos trabalhadores do campo, o que necessariamente a remete ao trabalho e ao embate entre projetos de campo que têm consequências sobre a realidade educacional e o projeto de país. Ou seja, precisamos considerar na análise que há uma perspectiva de totalidade na constituição originária da Educação do Campo.

Optamos por realizar a análise bibliográfica de documentos produzidos pelo próprio Movimento, junto com a legislação vigente no país referente à educação e, notadamente, à Educação do Campo. Também teremos como sustentação teórica estudos nas áreas da educação, sociologia, história e geografia, que nos permitem compreender os movimentos sociais do campo e as especificidades de uma ampla área de análise. 
Esta conduta, na medida do possível, estabelecerá uma pesquisa interdisciplinar sobre a "Proposta de Educação do MST" que "[...] permite não apenas a observação do fenômeno por uma lente grande-ocular como permite através da mobilidade que a sustenta, aproximação ou distanciamento do fenômeno estudado" (FAZENDA, 1994, p. 62), expandindo os métodos de investigação e os sistemas organizacionais dos estudos.

A integração da análise bibliográfica com a interdisciplinaridade possibilitará a construção de um conhecimento válido e confiável. Os procedimentos metodológicos aplicados ao trabalho não se limitam a um caminho a ser percorrido, mas fazem parte da produção do conhecimento e da ampliação dos estudos sobre o objeto em questão.

Nesse contexto, o primeiro passo será entendermos a amplitude dos objetos estudados, ou seja, de um lado, os movimentos sociais, representado pelo MST, e de outro, a educação, com um recorte na Educação do Campo. Ainda que os conceitos sejam apresentados em distintos momentos durante a redação, eles estarão sempre interpassados um pelo outro, em um processo de diálogos e conexões capazes de impulsionar a confluência entre conceitos e áreas do saber.

Pensarmos e repensarmos os processos educacionais do campo propostos pelo MST é uma maneira de constituirmos ações teóricas e práticas para entender o sistema educacional fora das esferas públicas ou privadas e fomentar o questionamento acerca dos valores e intenções da educação.

Através da compilação dos dados coletados, tanto na literatura científica nacional quanto internacional, teremos um arcabouço epistemológico-teórico para ser aplicado nos estudos sobre as propostas pedagógicas e as possibilidades plurais de educação permanente, seja no campo ou na cidade, de maneira formal ou não formal.

Desse modo, o teórico será medido pela precisão da prática, sendo que a primeira oferecerá conceitos e critérios para obtermos como resultado um processo metodológico para esboçar as distinções e semelhanças entre a Educação do Campo e a Proposta Pedagógica do MST. Também apresentará leis, bibliografia e fontes primárias que tratam do assunto e criem reflexões sobre os modelos adotados, quer pelo Movimento ou pelo poder público.

\section{DESENVOLVIMENTO}

A constituição dos movimentos sociais ocorre de maneira ativa e consciente, como algo intrínseco às relações humanas, criando experiências que formam a cultura por meio de tradições, valores, ideias e instituições.

Essa constatação se deve, nas palavras de Thompson (1999, p. 10-11), ao fato de que “[...] os fins são escolhidos pela nossa cultura, que nos proporciona, ao mesmo tempo, nosso 
próprio meio de escolher e de influenciar nessas escolhas". Assim, os movimentos sociais não ocorrem com base em estruturas determinadas, mas se constituem a partir de processos históricos compostos por saberes, informações e organização cultural, transmitidos pelas vivências e experiências coletivas.

Segundo Mattos (2012), da segunda metade do século XIX em diante, o estudo sobre a formação dos movimentos sociais e suas influências na vida coletiva e individual passou a ser um ponto fundamental nas pesquisas históricas e sociológicas.

No Brasil, podemos analisar os estudos dos movimentos sociais dividindo-os em dois períodos distintos. O primeiro período, anterior ao século XIX, tem como principais características: 1) a luta dos nativos pela organização socioeconômica; 2) as ações contra a escravidão africana e indígena; 3) os movimentos pela independência; e 4) as rebeliões contra o Império.

No segundo período, marcado pelo início da República e da urbanização do país, problemas sociais emergentes culminaram no surgimento de novos movimentos nos centros urbanos e no campo. Porém, foi apenas a partir de 1970 que tais movimentos passaram a receber maior relevância na política nacional e nos estudos sociológicos e históricos (SCHERER-WARREN, 1993).

A pesquisa sobre movimentos sociais, em suas distintas dimensões, despertou então o interesse da comunidade científica, tornando-se tema relevante de análises acadêmicas e com presença assegurada nos estudos historiográficos do país.

Entre os movimentos reconhecidamente sociais que obtiveram grande importância na historiografia brasileira e nos estudos acadêmicos, destaca-se o Movimento dos Trabalhadores Rurais Sem Terra, também conhecido como Movimento dos Sem Terra ou, simplesmente, MST. Sua formação decorre do acúmulo da luta agrária resistente no país ao longo dos anos e intensificada nas décadas de 1950 e 1960 com a criação das Ligas Camponesas da União dos Lavradores e Trabalhadores Agrícolas (ULTABs) e do Movimento dos Agricultores Sem Terra (MASTER).

Gestado entre o período de 1979 a 1984, o MST não se apoiou apenas na reforma agrária, mas tem entre seus objetivos alterar os "[...] problemas estruturais do nosso país, como a desigualdade social e de renda, a discriminação de etnia e gênero, a concentração da comunicação, a exploração do trabalhador urbano" (MST, 2020, não paginado).

Em meio ao fim da ditadura militar e início do processo de redemocratização do Brasil, o MST, como outros importantes acontecimentos deste período, teve “[...] o seu começo assinalado pelas experiências nas lutas populares, que desafiavam as formas institucionais" (FERNANDES, 1996, p. 50). Entre os anos de 1979 a 1984, ocorre a 
elaboração do MST, principalmente nas regiões centro-sul do país. Entretanto, sua formalização, enquanto movimento social organizado, aconteceu somente em 1984, na cidade de Cascavel, Paraná, durante o Primeiro Encontro Nacional de Trabalhadores Sem Terra, que se realizou entre os dias 21 a 24 de janeiro daquele ano.

O Encontro tinha como objetivo concatenar todas as categorias de trabalhadores rurais que lutavam para obter terras para plantar. Dessa forma, criou-se o movimento de estruturas nacionais com “[...] três objetivos principais: lutar pela terra, lutar pela reforma agrária e lutar por mudanças sociais no país.” (MST, 2020, não paginado). O movimento também assinalou, neste momento, que suas lutas não seriam apenas relacionadas com a Reforma Agrária, mas implicariam questões estruturais e políticas do país (FERNANDES, 2000).

Ao longo dos anos, com o crescimento de membros do MST e sua rápida expansão por grande parte do território nacional, foi necessário criar uma estrutura organizacional adequada às necessidades do Movimento. Este crescimento possibilitou a criação de uma estrutura básica em diversos estados brasileiros, formada essencialmente "[...] por uma coordenação, uma direção, uma secretaria e por setores que atendiam às necessidades prioritárias" (LOPES, 2004, p. 79).

O dinâmico processo formativo do MST e sua organicidade produzem e registram experiências dentro do cotidiano e, nesse contexto, apresenta um método pedagógico que busca compreender a realidade do trabalhador rural sem-terra, numa dinâmica que segue a lógica do próprio Movimento.

Para Lopes (2004), essas ações sempre representaram um esforço do Movimento em se reinventar política e organizacionalmente conforme a conjuntura; assim, uma de suas características consiste na constância de alterações em sua sistematização, sendo proativo e com continuidade intensa em suas ações informativas, educacionais, sociais e políticas.

Atualmente, o MST está presente em 24 estados da União, com mais de 350 mil famílias que, mesmo assentadas, continuam a se empenhar nas ações do Movimento. Além dos assentamentos e acampamentos, o MST conta com diversas cooperativas, associações e agroindústrias, que auxiliam na produção, distribuição e venda de alimentos, e, ainda, possui a colaboração da Escola Nacional de Formação Florestan Fernandes, que contribui para a formação do MST e de outras organizações.

A estruturação organizacional do Movimento é pautada pela cooperação, com a finalidade de garantir "[...] uma maneira de organizar a produção através da divisão do trabalho.” (MST, 2020, s/d).

Porém, a dinâmica é a característica insueta organizacional do MST, trazendo diversas alterações e ampliações em sua estrutura (NAVARRO, 2002). Segundo Lopes (2004), o MST 
possui grande flexibilidade, o que lhe possibilita se modificar conforme as necessidades impostas pela conjuntura política e social do momento e incorporar novos princípios e elementos. Desde o início, a educação é uma de suas linhas estruturadoras.

A educação sempre foi uma prioridade para os membros do MST. Por essa razão, o setor de educação foi criado em âmbito nacional após três anos de fundação do Movimento, com uma proposta que se desenvolveu a partir de dois eixos complementares: a luta pelo direito à educação e a construção de uma nova pedagogia.

Caldart (1997), depois de analisar o processo histórico de formação do setor de educação dentro do MST, no qual teve participação ativa, formulou alguns princípios que direcionaram a Educação do Campo nos assentamentos do MST, com destaque para os seguintes itens:

1) A educação que nós queremos/precisamos não acontece só na escola.

2) Nossa luta é por escolas públicas de qualidade.

3) Trabalhamos por uma escola que assume a identidade do meio rural.

4) Valorizamos as educadoras e os educadores.

5) Profunda crença na pessoa humana e na sua capacidade de formação e transformação.

6) Acreditamos numa educação que valorize o saber dos/as educandos/as.

7) Queremos educar para a cooperação.

8) Um currículo organizado com base na realidade e no seu permanente movimento.

9) Criação de Coletivos Pedagógicos.

10) Uma educação (se) alimente (d)a Utopia.

11) Enquanto seguimos a luta pelos nossos direitos já começamos a trabalhar com eles. (CALDART, 1997, p. 39).

Antes da apresentação dos objetivos que foram construídos na trajetória do setor de educação do MST, entre os anos de 1987 a 1996, temos a homologação da Lei de Diretrizes da Educação Nacional - LDB (Lei n. 9394/96), que possibilitou a superação do conceito de educação vinculado à ideia de ruralidade. Em outras palavras, ultrapassou o paradigma de educação para o favorecimento das elites e permitiu a implantação de uma Educação do Campo, que considera as peculiaridades do educando que vive na zona rural, como destacado no artigo 28:

$\mathrm{Na}$ oferta da Educação Básica para a população rural, os sistemas de ensino promoverão as adaptações necessárias à sua adequação, às peculiaridades da vida rural e de cada região, especialmente:

I - Conteúdos curriculares e metodologias apropriadas às reais necessidades e interesses dos alunos da zona rural;

II - Organização escolar própria, incluindo adequação do calendário escolar às fases do ciclo agrícola e as condições climáticas;

III - Adequação a natureza do trabalho na zona rural. (BRASIL, 1996, art. 28). 
Com a LDB, a necessidade de adequação da educação à realidade da zona rural passou a indicar metodologias condizentes com elementos essenciais para a Educação do Campo, como, por exemplo, o calendário (BRASIL, 1996).

Ao compararmos as propostas da LDB e do MST, encontramos o reconhecimento da diferença na modalidade de Educação do Campo. Percebendo a educação como um processo e um instrumento que acompanha e prepara para as mudanças sociais (BRANDÃO, 2007), as propostas apresentadas entre os anos de 1996 (MST) e 1997 (LDB) sofreram alterações em resposta às novas demandas da sociedade no século XXI, com ênfase na educação que respeite o aluno como protagonista.

O MST instituiu em seu projeto pedagógico o "[...] contraponto aos processos de exclusão social e que ajude a reconstruir a perspectiva histórica e a utopia de uma sociedade com justiça social e trabalho para todos" (CALDART, 2001, p. 209). Trouxe consigo o princípio da pedagogia em movimento e o movimento da pedagogia, que trabalha a integralidade do indivíduo e a prática radical de humanização com um sentido amplo e profundo da educação continuada, não apenas nas relações dentro da escola, mas reconhecendo os elementos edificantes existentes no ensino/aprendizagem no cotidiano.

Podemos pensar no próprio Movimento como um processo educativo (CALDART, 2001) em que o educando se utiliza da modalidade de Educação do Campo em um processo específico para uma educação que contemple as realidades de cada sujeito e fortaleça a autonomia e a criticidade.

Nessa perspectiva, a pedagogia do MST poderá ser estendida para a educação em outros locais e momentos do campo brasileiro, construindo-se dentro da práxis social.

O processo educacional dentro do MST assumiu não apenas a função de transmitir informações, mas de desenvolver um currículo que abrangesse as necessidades de uma Educação do Campo e contribuísse para a formação de sujeitos capazes de colaborarem com a construção de uma nova possibilidade societária (BAUER, 2016). Um currículo nestes moldes não pode ser construído de maneira homogênea e carece de elaboração democrática, capaz de respeitar aspectos sociais, culturais, geográficos e temporais.

$\mathrm{Na}$ interposição de elementos antagônicos de currículos específicos para a Educação do Campo, no ano de 2017, a versão final da Base Nacional Comum Curricular (BNCC) para a Educação Infantil e para o Ensino Fundamental temos essa modalidade apenas uma referência que não demostra a sua complexidade e a necessidade de pensar a Educação do Campo de maneira plural. Prevista no artigo $9^{\circ}$ da LDB e constituída por meio de audiências públicas regionais - realizadas em Manaus (AM), Recife (PE), Florianópolis (SC), São Paulo (SP) e Brasília (DF) -, a BNCC busca referenciar de maneira nacional uma: 
[...] formulação dos currículos dos sistemas e das redes escolares dos Estados, do Distrito Federal e dos Municípios e das propostas pedagógicas das instituições escolares, a BNCC integra a política nacional da Educação Básica e vai contribuir para o alinhamento de outras políticas e ações, em âmbito federal, estadual e municipal, referentes à formação de professores, à avaliação, à elaboração de conteúdos educacionais e aos critérios para a oferta de infraestrutura adequada para o pleno desenvolvimento da educação. (BRASIL, 2017, p. 8).

A BNCC tem o intuito de assegurar dez competências ${ }^{1}$ gerais para direcionar a aprendizagem do aluno. Tais competências são elementos que desenvolvem no aluno determinado senso investigativo e o protagonismo do processo de aprendizagem. Entre as competências, podemos destacar a ampliação da busca por conhecimento, o respeito à diversidade e o agir ético. Tais elementos condizem com a construção de uma educação integral, que vai além de conteúdos informacionais, na busca por compreender o educando com um ser em desenvolvimento, para o qual a educação tem papel fundamental.

Focada no desenvolvimento de competências, a BNCC tentou estabelecer um compromisso com a educação integral para a cidadania, voltada à formação de indivíduos capazes de analisar dados e informações fornecidas para a tomada de decisões éticas. De acordo com a BNCC, no que foi postulado até o presente momento, a concepção de Educação Integral reconhece:

[...] que a Educação Básica deve visar à formação e ao desenvolvimento humano global, o que implica compreender a complexidade e a não linearidade desse desenvolvimento, rompendo com visões reducionistas que privilegiam ou a dimensão intelectual (cognitiva) ou a dimensão afetiva. Significa, ainda, assumir uma visão plural, singular e integral da criança, do adolescente, do jovem e do adulto - considerando-os como sujeitos de aprendizagem - e promover uma educação voltada ao seu acolhimento, reconhecimento e desenvolvimento pleno, nas suas singularidades e diversidades. Além disso, a escola, como espaço de aprendizagem e de democracia inclusiva, deve se fortalecer na prática coercitiva de não discriminação, não preconceito e respeito às diferenças e diversidades. (BRASIL, 2017, p. 14).

Temos o desafio de superar o processo da escola tradicional, baseado em conteúdos delimitados e, muitas vezes, fechados dentro de uma disciplina, não promovendo uma integração dos saberes. Temos também a necessidade de reconhecermos as diversas possibilidades de ensino e aprendizagem que podem ser construídas pelos educadores e educandos.

No entanto, quando fazemos referência à Educação do Campo, há apenas uma citação, enquadrada na BNCC no âmbito do currículo escolar, que se encontra na introdução do texto (BRASIL, 2017). Em relação à construção do currículo, a BNCC valoriza a participação da

\footnotetext{
1 Para a BNCC, competência é “[...] definida como a mobilização de conhecimentos (conceitos e procedimentos), habilidades (práticas, cognitivas e socioemocionais), atitudes e valores para resolver demandas complexas da vida cotidiana, do pleno exercício da cidadania e do mundo do trabalho." (BRASIL, 2017, p. 8).
} 
comunidade escolar, dos alunos e dos professores na contextualização dos conteúdos, na organização interdisciplinar, na diversidade das práticas metodológicas, nos procedimentos de avaliação formativa, no uso das tecnologias e na defesa da formação e aprendizagem continuadas de educandos e educadores.

Após as considerações referentes à Educação do Campo na BNCC no tocante ao currículo, as demandas da modalidade se dirigem para as Diretrizes Curriculares Nacionais (DCN) publicadas em 2010. Então, as especificidades da Educação do Campo no conteúdo da BNCC, não são mais explícitas e restringe a matriz formativa generalizada, que não comporta diversidade das dimensões educacionais da modalidade.

Neste ponto, percebemos a amplitude da proposta curricular do MST para a educação dos educandos que moram no campo, se comparada a da BNCC. Ao centrar-se nas competências, esta proposta desconsidera o processo de construção de uma formação integral, como destaca Aguiar (2018) em sua análise acerca da resistência do Conselho Nacional de Educação à instituição da BNCC:

É preciso pensar a educação em sua totalidade. Temos a convicção de que currículo, a partir de diretrizes nacionais, é definido nas instituições educativas e escolas, construído a muitas mãos, a partir das várias histórias de vida que fazem parte desse cotidiano. As concepções, saberes, conteúdos e as metodologias não fazem sentido se desconectadas daquele contexto. Os estudantes e os profissionais da educação devem ter assegurados seu protagonismo. É preciso refundar saberes, ampliando, verdadeiramente, o conhecimento da realidade, como delineado nos dispositivos legais e nas Diretrizes Curriculares Nacionais (DCN) para a Educação Básica. (AGUIAR, 2018, p. 17).

Percebemos, portanto, que a proposta da BNCC colabora para a constituição de um abismo entre a realidade escolar e um currículo que contemple a Educação do Campo. Em contrapartida, ao olhar para a realidade dos trabalhadores, jovens e crianças do campo, o MST exalta o protagonismo de todos, indo de encontro ao modelo de educação homogeneizadora encontrado na proposta da BNCC.

Ao centrar a educação em competências, a BNCC marginaliza a construção dos conhecimentos e a dinâmica singular de aprendizagem de cada educando. Esse fator se agrava ainda mais quando pensamos em uma Educação do e no Campo, pois as vivências são distantes e ímpares, não podendo ser retidas em um reducionismo curricular ou de competências mecanicistas.

Com base nisso, concluímos que a BNCC não está atrelada a uma educação integral que respeite o educando e seu meio, mas a avaliações externas e padronização de conteúdos contrários à pluralidade da educação, conforme destacam Dourado e Oliveira (2018, p. 41): 
habilidades e competências, permitindo maior atrelamento da BNCC às avaliações externas. Além disso, observa-se subtração da autonomia, da diversidade e da localidade em detrimento da centralização curricular, cujos planejadores da política federal assumem as definições e os mecanismos de sua implementação por meio do financiamento, da gestão centralizada, da avaliação, da formação de professores, entre outros.

Então, comparando a BNCC e as propostas pedagógicas do MST, verificamos a diferença entre uma metodologia educacional centrada notadamente em competências e outra voltada para o aluno numa perspectiva de educação integral.

Face ao exposto, defendemos que a modalidade de Educação do Campo pode e deve ser pensada de maneira ampla e não circunscrita às competências, pois temos a premente necessidade de ampliarmos a diversidade de uma educação que reconheça o aluno para além da preparação para o mercado de trabalho com vistas à formação cidadã para o mundo.

\section{CONSIDERAÇÕES FINAIS}

A modalidade de Educação do Campo não se limita ao ato de transmitir uma informação, pois se associa e é inerente aos fenômenos culturais que constituem a sociedade e os grupos sociais que a compõem.

Nessa perspectiva, ressaltamos que é impossível entender a educação desassociada da organização cultural do campo. De modo semelhante, não conseguimos analisar a aprendizagem sem o estudo dos processos educacionais e o entendimento da realidade do educando que não está inserido no cotidiano de uma vida urbana.

A constituição ontológica da sociedade e dos indivíduos se dá a partir de uma interação educativa, que será mediada por conteúdos programáticos decifrados, transformados e codificados dentro da estrutura específica, neste caso, do campo. Isso requer a necessidade de um sentido cultural no ato de educar e na interação dos condicionantes socioculturais de ressignificação dos símbolos que provêm da vida em sociedade.

Nesta elaboração conceitual, a Educação do Campo parte de atos reflexivos e socialmente construídos, conforme analisamos na proposta apresentada pelo MST, o que implica a coparticipação ativa dos sujeitos envolvidos, que não apenas recebem a informação, mas a codificam, interpretam e transmitem de maneira dialética. Portanto, comungamos com o pensamento de Freire (1971, p. 44) ao ressaltar que:

Todo ato de pensar exige um sujeito que pensa, um objeto pensado, que mediatiza o primeiro sujeito do segundo, e a comunicação entre ambos, que se dá através de signos linguísticos. O mundo humano é, desta forma, um mundo de comunicação. 
A Educação do Campo se faz criticamente dentro de uma ação e produção dos sujeitos envolvidos, a que denominamos cultura, representada “[...] como aquisição sistemática da experiência humana" (FREIRE, 1981, p. 190). Nesse sentido, não deve estar restrita a um reducionismo curricular ou de competências.

Percebemos que a proposta do MST em suas ações pedagógicas para o campo ultrapassa a perspectiva da BNCC, pois transforma o educando em protagonista social e permite a educação para a mudança. Nessa direção, temos a possibilidade de superar a barreira da formação padronizadora que produz mão de obra a serviço do mercado de trabalho em prol da formação integral, com potencial para criar sujeito críticos, autônomos e cidadãos pensantes para um mundo plural, seja ele do trabalho, da convivência ou da solidariedade.

Em contrapartida, a BNCC, ao tratar as competências como finalidade educacional, inviabiliza a educação integral que tanto almejamos para uma sociedade ética e igualitária. Não obstante, vemos surgir em movimentos sociais, como o MST, um paradigma de educação cujas ações - início, meio e fim - estão centradas no ser humano e seu protagonismo na história e na formação de um mundo melhor para todos com responsabilidade cidadã e comprometimento social.

\section{REFERÊNCIAS}

AGUIAR, M. A. Relato da resistência à instituição da BNCC pelo conselho nacional de educação mediante pedido de vista e declarações de votos. In: AGUIAR, Márcia Ângela da S.; DOURADO, Luiz Fernandes [org.]. A BNCC na contramão do PNE 2014-2024: avaliação e perspectivas [Livro Eletrônico]. Recife: ANPAE, 2018. Pág. 8 a 22.

BAUER, Carlos. Educação, terra e liberdade: princípios educacionais do MST em perspectiva histórica. Jundiaí: Paco Editorial, 2016.

BRANDÃO, Carlos. Território e Desenvolvimento: as múltiplas escalas entre o local e o global. São Paulo: Editora da Unicamp, 2007

BRASIL. Ministério da Educação. Base Nacional Comum Curricular. Disponível em: <http://basenacionalcomum.mec.gov.br/>. Acesso em: 24 abr. 2021.

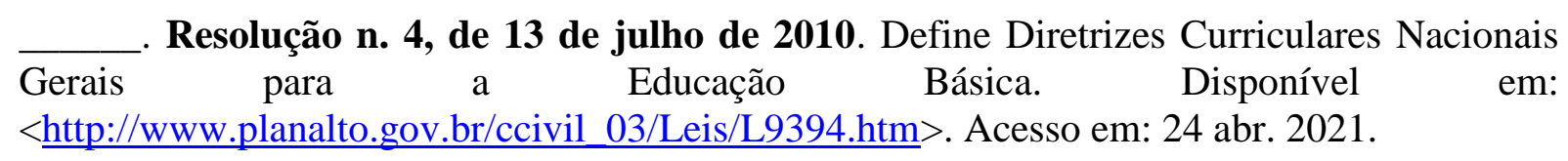

. Senado Federal. Lei das Diretrizes e Bases da Educação Nacional. Lei n. 9394, de 20 de dezembro de 1996. Estabelece as diretrizes e bases da educação nacional. Disponível em: <http://www.planalto.gov.br/ccivil_03/Leis/L9394.htm>. Acesso em: 24 abr. 2021.

CALDAR, Roseli Salete. O MST e a formação dos sem-terra: o movimento social como princípio educativo. Estudos avançados, v. 15, n. 43, p. 207-224, 2001.

Educação do Campo: notas para uma análise de percurso. Trabalho, Educação e Saúde, Rio de Janeiro, v. 7, n. 1, p. 35-64, 2009. 
Educação em movimento: formação de educadoras e educadores no MST. Petrópolis: Vozes, 1997.

DOURADO, Luiz Fernandes; OLIVEIRA, José Ferreira de. Base Nacional Comum Curricular (BNCC) e os impactos nas políticas de regulação e avaliação da educação superior. In: AGUIAR, Márcia Ângela da S.; DOURADO, Luiz Fernandes [org.]. A BNCC na contramão do PNE 2014-2024: avaliação e perspectivas [Livro Eletrônico]. Recife: ANPAE, 2018. Pág. 38 a 43.

FAZENDA, Ivani Catarina Arantes. Interdisciplinaridade: história, teoria e pesquisa. Campinas/SP: Papirius, 1994

FERNADES, Bernardo Maçano. MST: formação e territorialização em São Paulo. Sao Paulo: Editora Hucitec, 1996.

FERNANDES, Bernardo Mançano. Os campos da pesquisa em Educação do Campo: espaço e território como categorias essenciais. In: Ministério da Educação (Org.). Educação do Campo e pesquisa: questões para reflexão. Brasília: Ministério do Desenvolvimento Agrário, 2006. p. 27-40.

FREIRE, Paulo. Ação Cultural para a liberdade. Rio de Janeiro: Paz e Terra, 1981.

Extensão ou comunicação? Rio de Janeiro: Paz e Terra, 1971.

LOPES, Fábio Júnior. A reinvenção política do MST: uma análise do programa de reforma agrária do movimento dos trabalhadores rurais sem terra ao longo da sua história. 197 f. 2004. Dissertação (Mestrado em Ciências Sociais) - Faculdade de Filosofia e Ciências, Universidade Estadual Paulista, Marília, 2004.

MOVIMENTO DOS TRABALHADORES RURAIS SEM TERRA. História do MST. Disponível em: <http://www.mst.org.br/historico/historia5.html〉. Acesso em: 02 out. 2020.

NAVARRO, Zander. A experiência do MST na cooperação agrícola. In: STÉDILE, João Pedro (org.). A questão agrária no Brasil: Interpretações sobre o camponês e o campesinato. São Paulo: Editora Expressão Popular, 2005.

Mobilização sem emancipação: as lutas sociais dos sem-terra no Brasil. In: SANTOS, Boaventura de Souza (org.). Produzir para viver: os caminhos da produção nãocapitalista. Rio de Janeiro: Civilização Brasileira, 2002a, p. 189-232.

THERRIEN, J.; DAMASCENO, M. N. Educação e escola no campo. Papirus, Campinas, 1993. p. 15-51.

THOMPSON, Edward Palmer. A formação da classe operária inglesa. Rio de Janeiro: Paz e Terra, 1987.

Artigo Recebido: 29 de março de 2021.

Artigo Aceito: 02 de maio de 2021. 